\title{
LÉXICO DE LA HEROICIDAD EN GRIEGO Y EN SÁNSCRITO
}

\author{
Roberto Morales Harley
}

\section{(9) $\mathbb{P Q \Theta \Theta}$}

Doi: https://doi.org/10.15517/rfl.v46i1.41159

URL: https://revistas.ucr.ac.cr/index.php/filyling/index 



\title{
LÉXICO DE LA HEROICIDAD EN GRIEGO Y EN SÁNSCRITO
}

\author{
VOCABULARY ABOUT HEROISM \\ IN GREEK AND SANSKRIT
}

Roberto Morales Harley

\begin{abstract}
RESUMEN
Se propone un análisis del léxico referido a la noción de "heroicidad" tanto en griego antiguo como en sánscrito clásico. Se establecen tres objetivos: (1) analizar la familia léxica derivada del sema ì $\omega$ - y el campo semántico de la heroicidad en griego, (2) analizar la familia léxica derivada del sema वीर ( $(v \bar{t} r-)$ y el campo semántico de la heroicidad en sánscrito, y (3) contrastar las nociones de heroicidad. Con base en los diccionarios de Bailly (2000) y Monier-Williams (2008), se elaboran dos corpora para el estudio. En conclusión, se postula una noción griega de heroicidad como "(in) mortalidad" y una noción india de heroicidad como "liberación".

Palabras clave: familia léxica; campo semántico; heroicidad; lengua griega; lengua sánscrita.
\end{abstract}

\begin{abstract}
The paper proposes an analysis of the vocabulary referred to the notion of "heroism" both in ancient Greek and classical Sanskrit. It stablishes three objectives: (1) to analyze the lexical family derived from the seme $\dot{\eta} \rho \omega$ - and the semantic field of heroism in Greek, (2) to analyze the lexical family derived from the seme वीर ( $v \bar{\imath} r$-) and the semantic field of heroism in Sanskrit, and (3) to contrast the notions of heroism. Based on the dictionaries by Bailly (2000) and Monier-Williams (2008), it elaborates two corpora for the study. In conclusion, it states a Greek notion of heroism as "(in) mortality" and an Indian notion of heroism as "liberation".
\end{abstract}

Keywords: lexical family; semantic field; heroism; Greek language; Sanskrit language.

\section{Introducción}

El Diccionario de la Lengua Española brinda la siguiente información sobre la voz héroe:

\section{héroe, ína}

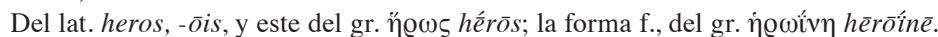

1. m. y f. Persona que realiza una acción muy abnegada en beneficio de una causa noble.

2. $\mathrm{m}$. y f. Persona ilustre y famosa por sus hazañas o virtudes.

M. L. Roberto Morales Harley. Profesor de la Escuela de Filología, Lingüística y Literatura. Universidad de Costa Rica. San José, Costa Rica.

Correo electrónico: roberto.moralesharley@gmail.com

Recepción: 11- 06- 18

Aceptación: 07- 12- 18 


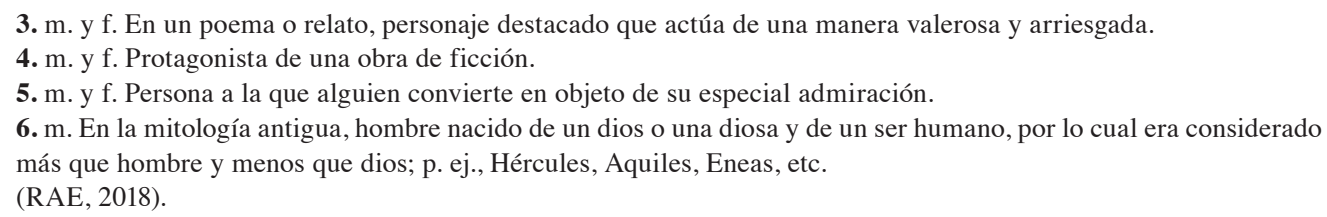

Las primeras dos acepciones enfatizan la orientación práctica de la heroicidad: la acción, las hazañas. Asimismo, sugieren la existencia de una ideología heroica: una causa, unas virtudes. La tercera acepción, referida a un poema (épico, se sobreentiende), añade la noción de valor, tan característica del héroe en el mundo antiguo. A su vez, la cuarta acepción es, en esencia, una extensión del sentido recién discutido: si bien el héroe por antonomasia es el épico, a este le siguen, primero, el héroe trágico y el héroe cómico, y, después, el héroe de una novela o, incluso, de una película, por no mencionar a los siempre vigentes superhéroes. Estas últimas ideas se aproximan más a la quinta acepción: "mi papá es mi héroe” o "mi mamá es mi heroína", por ejemplo.

Todos los sentidos abordados remiten tanto al masculino como al femenino del sustantivo. No obstante, la última acepción, circunscrita a la mitología antigua, solo se registra en masculino. Como se evidencia mediante la etimología, la palabra se remonta al ámbito grecolatino, donde un héroe representa una suerte de ser intermedio: superior al común de los seres humanos pero inferior a los dioses. Tal ambivalencia se explica, en los relatos míticos, por un nacimiento de padres pertenecientes a esferas distintas. Entre los ejemplos ofrecidos, cabe destacar que dos son griegos -Hércules (en realidad, Heracles) y Aquiles- y el otro es romano -Eneas-. En adición, uno remite propiamente a un entorno mítico -Hércules- y los otros dos a la literatura épica -Aquiles y Eneas-.

En latín (Segura, 2003, p. 337), hèrōs, -ōis es un sustantivo masculino con dos sentidos: uno literal, de "héroe", "semidiós", "de la edad mítica [epíteto de los personajes épicos]”; y otro figurado, de "referente a un hombre célebre". Por su parte, en griego (Bailly, 2000, p. 909),

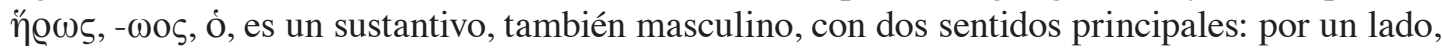
"amo", "jefe", "noble"; por otro, "semidiós". En el primero, se puede referir no solo a los jefes militares de los griegos al frente de Troya, sino también a cualquier combatiente o a cualquier hombre considerado noble por su nacimiento, su coraje o su talento. En el segundo, puede además ser, por extensión, cualquier hombre elevado al rango de semidiós o cualquier hombre en su condición de mortal.

En última instancia, estas voces derivarían de la raíz indoeuropea (Watkins, 2000, p. 76) ser- $^{-}$, "proteger": el grado aumentado $s \bar{e} r$-, con el sufijo formador de sustantivos -ōs, daría origen a la forma *sēr-ōs-, "héroe". De esta misma raíz, proceden, por vía del latín servāre, los verbos españoles conservar, observar, preservar, reservar.

Esta breve revisión etimológica evidencia que los sentidos de la heroicidad en español guardan estrecha relación con los que se encuentran en griego. Sin embargo, la lengua sánscrita, pese a la raíz indoeuropea que comparte, se desarrolla en un contexto diferente del que proveyó la tradición clásica en Occidente. En consecuencia, conviene llevar a cabo dos análisis léxicos separados, uno en griego y otro en sánscrito, a fin de contrastar, posteriormente, la información hallada. Para ello, se observan las siguientes consideraciones metodológicas:

[1] [...] En los estudios léxicos, creemos conveniente contemplar los dos planos del signo lingüístico: el de la expresión (significante) y el del contenido (significado) [...] 
[2] [...] Los estudios léxicos serán siempre limitados a una parte de éste, extraídos de los textos y corpus utilizados, ya que el léxico es un conjunto ideal inabarcable [...]

[3] [...] En el estudio y observación del léxico de una lengua aportan puntos de vista complementarios la Semántica, la Lexicografía y la Lexigrafía [...]

[4] [...] De los estudios realizados se desprende que el léxico posee una estructura ya que sus unidades no se hallan formando un conglomerado incoherente sino ocupando un punto determinado en esa estructura y un valor relacional [...]

(Artigas, 1998, pp. 30-31).

Para contemplar los dos planos del signo lingüístico [1], se mantiene la grafía de las voces, en alfabeto griego o en escritura devanāgarī (transliterada según las normas de la IAST), según el caso. El corpus [2] se integra, por un lado, con la familia léxica derivada del

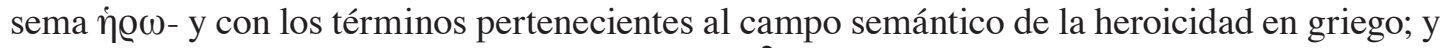
por otro, con la familia léxica derivada del sema वीर् (vīr-) y con los términos pertenecientes al campo semántico de la heroicidad en sánscrito. Se parte de la Semántica [3], de acuerdo con lo sentidos registrados en los diccionarios de Bailly (2000) y Monier-Williams (2008). Por último, el trabajo comparativo permite contrastar la estructura de las unidades léxicas [4].

\section{Léxico griego}

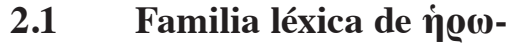

En Bailly (2000, p. 909), se registran las siguientes voces:

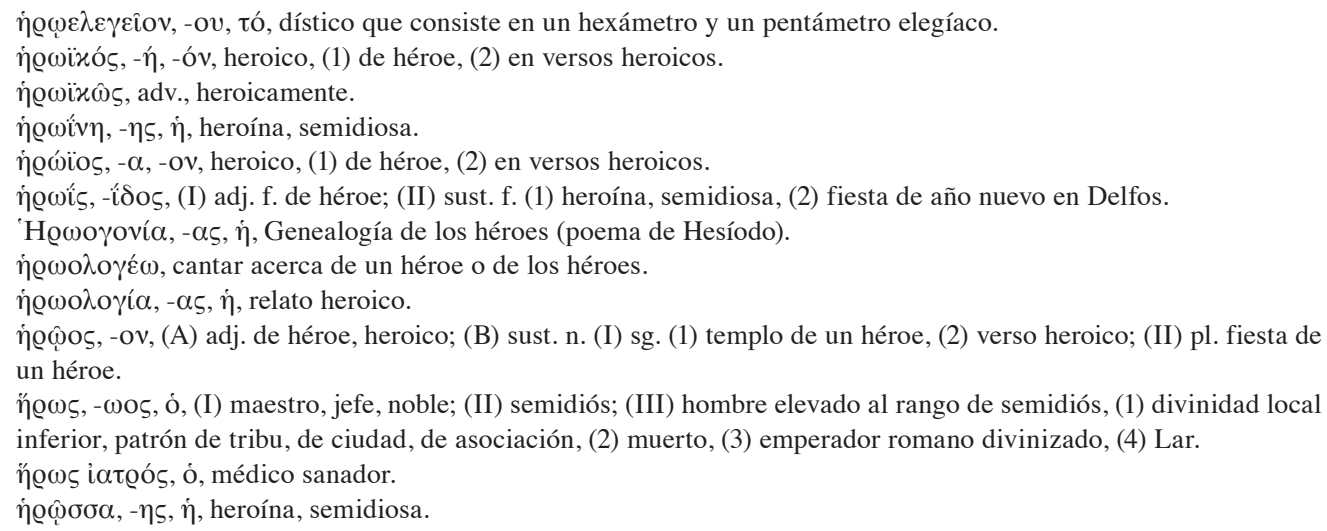

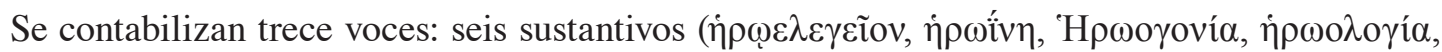

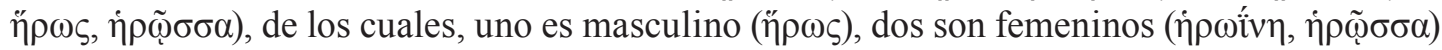

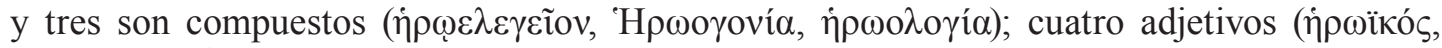

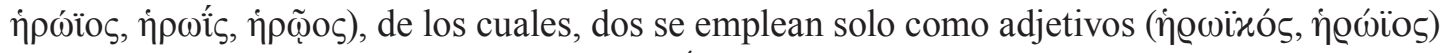

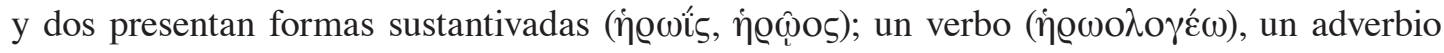

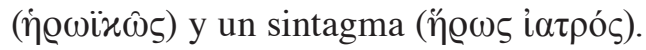

La voz principal es ク̋ (1) "maestro, jefe, noble" (Homero, Ilíada, 2, 110; Homero, Odisea, 1, 101); (2) "semidiós" (Hesíodo, Trabajos y días, 170); y (3) "hombre elevado al rango de semidiós" (Heródoto, Historia, 5, 105). El primer sentido se puede referir a los jefes militares de los griegos en Troya, a los combatientes de dicha expedición o a cualquier hombre noble por nacimiento, 
coraje o talento. A su vez, el tercer sentido se emplea para divinidades locales inferiores; para patrones de tribus, ciudades o asociaciones; para los muertos en general; para los emperadores romanos divinizados; o como traducción del latín Lares. Liddell y Scott (1843), con referencias a fuentes muy similares, registran los sentidos de (1) "héroe", (2) "la cuarta edad de los

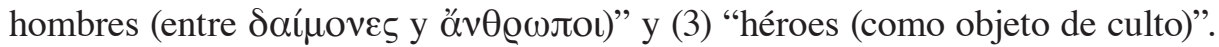

Como explica West (2007) para el ámbito indoeuropeo, héroe no es un término técnico de la mitología o la literatura, sino uno de conveniencia dentro de un particular entorno de valores culturales:

\begin{abstract}
'Héroe' no es, evidentemente, un término técnico, sino uno de conveniencia. Con este, designamos generalmente a un hombre de fuerza física y resistencia superiores, unidas a cualidades morales, tales como valentía, determinación y propensión a lanzarse a empresas peligrosas y abrumadoras. Despliega sus habilidades sobre todo al pelear con enemigos de una u otra clase (West, 2007, p. 411; traducción propia).
\end{abstract}

\title{
2.2 Campo semántico de la heroicidad en griego
}

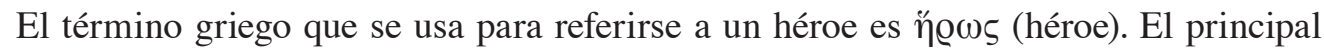

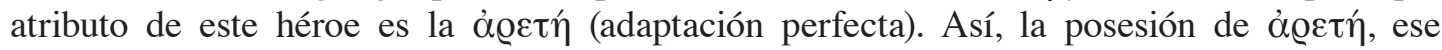

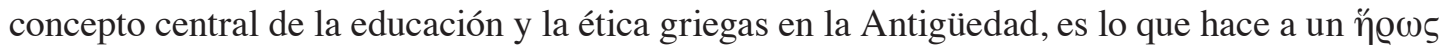

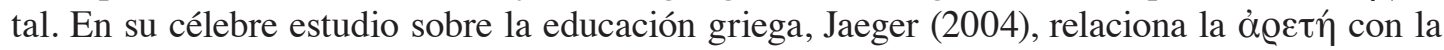
virtud, con un ideal caballeresco, con una conducta cortesana y con el heroísmo guerrero:

\footnotetext{
El tema esencial de la historia de la educación griega es más bien el concepto de areté, que se remonta a los tiempos más antiguos. El castellano [alemán, en el original] actual no ofrece un equivalente exacto de la palabra. La palabra "virtud" en su acepción no atenuada por el uso puramente moral, como expresión del más alto ideal caballeresco unido a una conducta cortesana y selecta y al heroísmo guerrero, expresaría acaso el sentido de la palabra griega (Jaeger, 2004, pp. 20-21).
}

Por su parte, Lasso de la Vega (1963), al abordar la ética homérica, vincula la ỏ@etí con otros términos de este código de conducta: "Los términos específicos de valor aplicados a

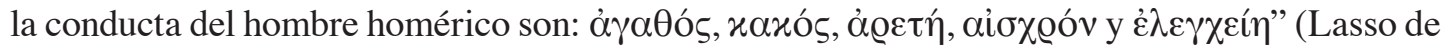

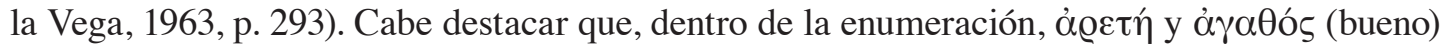

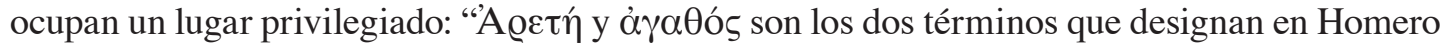
las cualidades humanas más altamente estimadas" (Lasso de la Vega, 1963, p. 291). Estas dos

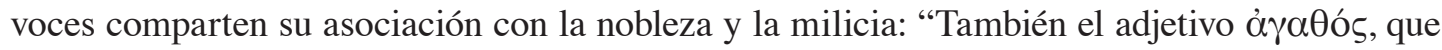
corresponde al sustantivo areté, aunque proceda de otra raíz, llevaba consigo la combinación

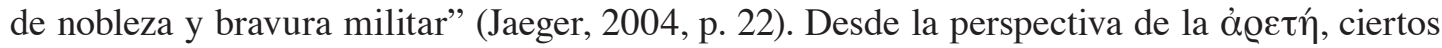
atributos indican una valoración positiva, mientras que otros evidencian lo contrario: $\alpha \gamma \alpha \theta$ ós

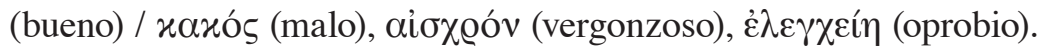

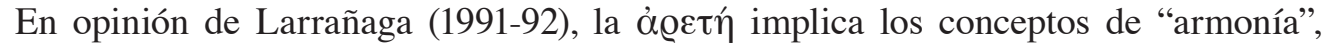
"excelencia", "herencia", "esfuerzo", "moral agonal”, "honor”, "recompensa", "gloria”, "opinión”, "divinidad", "destino" y "muerte". Tras estas consideraciones, se procederá a analizar trece voces del campo semántico de la heroicidad en griego.

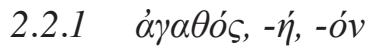

De acuerdo con Bailly (2000, pp. 4-5), es “bueno, de buena calidad”. Referido a personas, significa (1) "noble, de buen nacimiento" (Homero, Ilíada 21, 109), (2) "valiente" 
(Homero, Ilíada 1, 131), (3) "bueno, destacado en su género" (Homero, Ilíada 3, 179) y (4) "bueno (en sentido moral)" (Tucídides, Historia de la guerra del Peloponeso 1, 37). A su vez, referido a cosas, significa (1) "bueno, destacado en su género" (Homero, Odisea 15, 506), (2) "conveniente, útil" (Homero, Odisea 17, 352), (3) "propicio, favorable" (Jenofonte, Económico 11) y (4) "próspero, dichoso" (Jenofonte, Económico 12).

El comparativo ỏ $\mu \varepsilon i ́ v \omega v, ~-o v ~(B a i l l y, ~ 2000$, p. 96) es “más fuerte, más valiente, más virtuoso (referido a personas)" o "de mejor calidad, más precioso (referido a cosas)". Por su

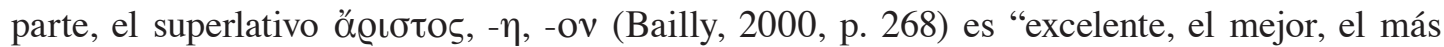
valiente, el más noble". Como indica Berenguer (2002, p. 55), el adjetivo cuenta con tres formas de comparativo y de superlativo, empleadas para sendos sentidos: de $\alpha \gamma \alpha \theta$ ó $\varsigma$ (bueno),

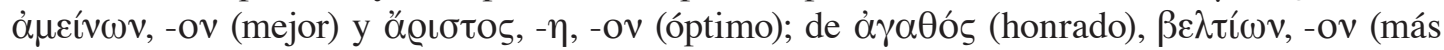

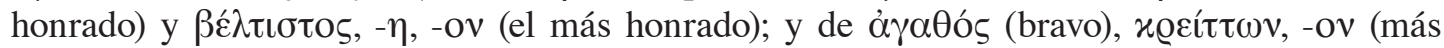

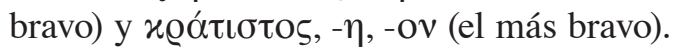

El mismo valor convencional que West (2007) reconoce para héroe, lo sugiere Montes

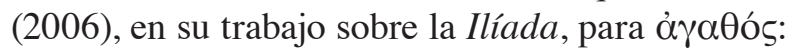

’A $\gamma \alpha \theta$ ó funciona en el poema, según mi opinión, como adjetivo absoluto, esto es, incluye aquellas cualidades que la sociedad promociona y que valora en sus agentes por encima de todas, lo que quiere decir que un adjetivo que significa "bueno" termina por discriminar qué es bueno y qué no lo es de acuerdo con los parámetros de valor social. Aquél que exhiba dichas cualidades predeterminadas será, en términos generales, "bueno". Lo mismo puede decirse,

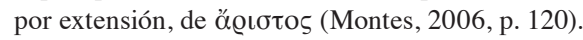

\subsection{2 $\dot{\alpha} \gamma \omega \dot{\omega} v,-\tilde{\omega} v o \varsigma, \dot{o}$}

Como señala Bailly (2000, p. 21), puede ser (1) “asamblea, reunión” (Homero, Ilíada 7 , 298), (2) "asamblea para los juegos públicos" (Homero, Ilíada 23, 258) y (3) "lucha, combate" (Sófocles, Traquinias 20, 159). Los certámenes por excelencia eran los juegos Olímpicos, en honor a Zeus; los Píticos, en honor a Apolo; los Ístmicos, en honor a Poseidón; y los Nemeos, en honor a Heracles. En una cultura de la vergüenza (Dodds, 1986) como la de la Grecia homérica, la moral es de carácter agonal (Larrañaga, 1991-92, p. 83).

\subsection{3 $\dot{\alpha} \rho \varepsilon \tau \dot{\eta},-\tilde{\eta} \varsigma, \dot{\eta}$}

De acuerdo con Bailly (2000, pp. 263-264), es un "mérito o cualidad por la cual se sobresale". Puede ser de dos tipos: (1) "cualidad del cuerpo", como fuerza y agilidad (Homero, Ilíada 20, 411), belleza (Jenofonte, Ciropedia 5, 1, 4) o salud (Platón, Gorgias 479b); y (2) "cualidad de la inteligencia, del alma", como coraje (Heródoto, Historia, 8, 92), virtud (Platón, República 618b) o consideración y honor (Sófocles, Filoctetes 1420). En el primer sentido, se emplea para personas, dioses, animales e, incluso, cosas; en el segundo, únicamente para personas.

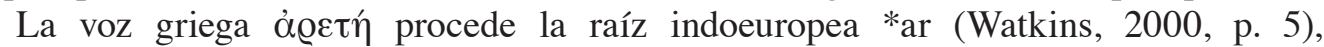

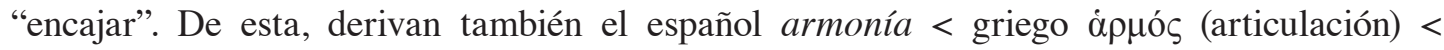

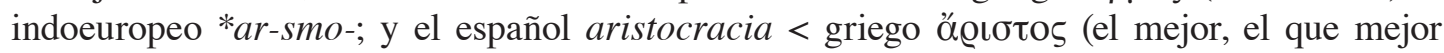
encaja) < indoeuropeo *ar-isto-. Por ello, Larrañaga (1991-92) propone traducir ả@etí como "adaptación perfecta":

La areté caballeresca significa pues etimológicamente 'adaptación perfecta'. Es la adaptación perfecta del ser, de toda la existencia de un hombre a la idea primigenia, perfecta, que Dios se ha forjado de él al crearlo. La areté es la realización, la puesta en acto de todas las potencias de ese ser, de ese hombre; ella abarca al hombre total (Larrañaga, 1991-92, pp. 66-67). 


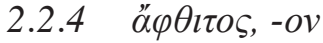

Según Bailly (2000, p. 325), es “incorruptible, imperecedero, inmortal”, referido tanto a los dioses (Hesíodo, Teogonía 389) como a los seres humanos (Esquilo, Euménides 724). Incluso se puede usar para cosas (Homero, Ilíada 18, 370). En combinación con $x \lambda \hat{\varepsilon}$ os, forma

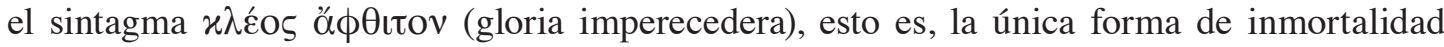
accesible para los mortales. Esta fórmula homérica (West, 2007), como indicó el filólogo alemán Adalbert Kuhn en 1853, encuentra un paralelo en la fórmula védica śravo 'kșitam (gloria imperecedera).

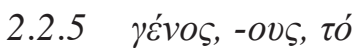

De acuerdo con Bailly (2000, p. 396), cuenta con dos sentidos principales: (1) "nacimiento" (Homero, Ilíada 3, 215) y, en general, "origen, descendencia" (Homero, Ilíada 13, 354); (2) "raza, género, especie" (Homero, Ilíada 12, 23) y, en el caso de los seres humanos, "raza, familia, parentesco" (Homero, Odisea 8, 583). El linaje, divino o noble, constituye una condición previa para el desarrollo del héroe griego.

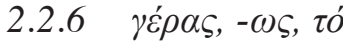

Como señala Bailly (2000, p. 398), es (1) "regalo ofrecido como marca de honor" (Homero, Odisea 7, 10), (2) "marca de honor, honores rendidos a un muerto" (Homero, Ilíada 16, 457) y (3) "prerrogativa, privilegio honorífico" (Homero, Ilíada 4, 323). Con respecto a su uso para referirse a Briseida, el regalo ofrecido a Aquiles como marca de su honor, Nagy (1999) explica lo siguiente:

En este caso en particular, por supuesto, el géras es una muchacha cautiva. En el resto de la Ilíada, sin embargo, la misma palabra se refiere a la ración de carne cortada, le morceau du héros [sc. la porción del héroe], otorgada al guerrero más preminente del momento (Nagy, 1999, p. 132; traducción propia).

\subsection{7 $\delta \dot{\xi} \xi \alpha,-\eta \varsigma, \dot{\eta}$}

Según Bailly (2000, p. 531), es (1) “opinión” (Esquilo, Persas 29) y (2) "buena o mala opinión acerca de alguien, reputación” (Eurípides, Helena 847). En una cultura de la vergüenza

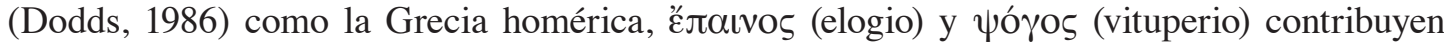
a delimitar la imagen del héroe. Posteriormente, en la retórica griega, estos términos hacen referencia a las dos especies del género epidíctico.

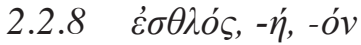

Referido a personas (Bailly, 2000, p. 814), significa (1) "honrado, honesto" (Homero, Odisea 22, 415), (2) "valeroso, viril" (Homero, Odisea 16, 263), (3) "noble, de linaje noble" (Sófocles, Antígona 38), (4) "rico" (Hesíodo, Trabajos y días 212), (5) "hábil” (Homero, Ilíada 15, 283) y (6) "sensato, sabio, prudente" (Homero, Ilíada 2, 272). Por su parte, referido a cosas (Bailly, 2000, p. 814), significa (1) "eficaz, útil” (Homero, Ilíada 1, 108), (2) "dichoso, favorable" (Homero, Odisea 24, 311) y (3) "precioso" (Homero, Ilíada 9, 330). 


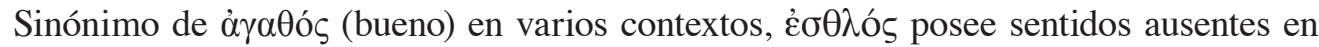
aquel adjetivo: honradez (como un tipo de bondad moral) y riqueza (como una forma de destacar en el ámbito social). Cabe destacar que, tanto en el contexto épico como en el clásico, bondad y belleza son conceptos indisolubles, a los cuales se suma también la nobleza. Así, de la frase $x \alpha \lambda$ òs $x \alpha \grave{~} \alpha \gamma \alpha \theta$ ós (bello y bueno) se forma, por crasis, el sustantivo $x \alpha \lambda$ ox $\alpha \gamma \alpha \theta i ́ \alpha$ (nobleza).

\subsection{9 $\theta \varepsilon o ́ \varsigma,-o \tilde{v}, \dot{o}$}

Puede ser, según Bailly (2000, p. 926), en general, “dios, la divinidad” (Homero, Ilíada 9, 49) o, en particular, "una divinidad” (Eurípides, Ifigenia en Áulide 413). En la épica homérica, Lesky (1989, pp. 88-96) propone tres antinomias para definir el accionar divino: (1) proximidad / lejanía, puesto que los dioses son antropomórficos, pero pertenecen a una esfera distinta; (2) favor / crueldad, dado que ayudan a los guerreros del bando al que pertenecen, pero son despiadados con los enemigos; y (3) justicia / arbitrariedad, en tanto solo son justos con sus favoritos y suelen actuar por conveniencia. En la jerarquía cósmica, los dioses se encuentran por encima de los héroes y por debajo del destino.

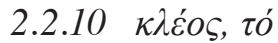

Defectivo en tanto carente de casos oblicuos, significa (Bailly, 2000, p. 1099) (1) "ruido, noticia que se esparce" (Homero, Ilíada 2, 584) y (2) "buen renombre, gloria" (Homero, Ilíada 4, 197). Con este último valor, suele ir acompañado de un adjetivo: $x \lambda \hat{\varepsilon}$ os $\dot{\varepsilon} \sigma \theta \lambda$ óv

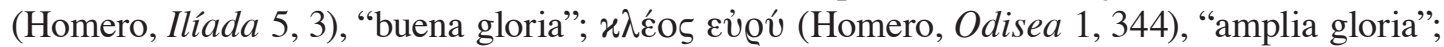

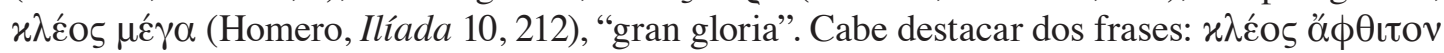

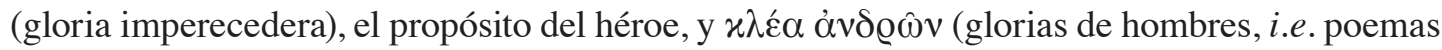
épicos), el medio por el cual el héroe alcanza su propósito.

\subsubsection{1 $\pi \rho o ́ \mu \alpha \chi o \varsigma,-o v$}

Este adjetivo significa (Bailly, 2000, p. 1645) "que combate en primer fila" (Homero, Ilíada 3, 31) y "que combate por, defensor de" (Esquilo, Siete contra Tebas, 418).

\section{$2.2 .12 \tau \iota \mu \eta^{\prime},-\tilde{\eta} \varsigma, \dot{\eta}$}

Posee cuatro sentidos principales (Bailly, 2000, pp. 1933-1934): (1) “evaluación, estimación" (Platón, Las leyes 914c), (2) "premio que se fija, honor" (Homero, Ilíada 1, 510), (3) "lo que se honra, objeto de estima, de respeto, de autoridad" (Esquilo, Agamenón 44) y (4) "pena, castigo, venganza" (Homero, Odisea 14, 70). Constituye el reconocimiento inmaterial que se sigue de la compensación materializada en $\gamma$ ćoas (compensación).

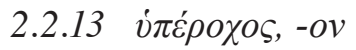

En Bailly (2000, p. 2007), se indica que su sentido es "que lleva sobre, superior"

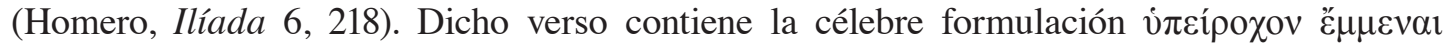
$\ddot{\alpha} \lambda \lambda \omega \nu$ (ser superior a los demás), que habitualmente se menciona en latín como primus inter pares (esse) -(ser) el primero entre los iguales-, en alusión a la figura de Agamenón. 


\section{Léxico sánscrito}

\subsection{Familia léxica de वीर् (vīr-)}

\section{En Monier-Williams (2008, pp. 1005-1007), se registran las siguientes voces:}

वीर (vīra), m. hombre, hombre valiente o eminente, héroe, jefe, esposo, hijo, macho, adepto, (dram.) heroísmo (uno de los 8 rasas), actor, fuego, fuego sagrado o sacrificial; $\mathrm{mfn}$. heroico, poderoso, fuerte, excelente, eminente. वीरकरा (vīrakarā), f. que produce héroes.

वीरकर्म (vīrakarma), n. que realiza acciones viriles, miembro viril. वीरकर्मन् (vīrakarman), n. hecho varonil. वीरकाम (vīrakāma), mfn. que desea descendencia masculina. वीरकीट (vīrakīṭa), m. gusano de héroe, guerrero deplorable. वीरकक्षि (vīrakukși), f. que lleva hijos en su vientre.

वीरगति (vīragati), f. morada de héroes.

वीरगोत्र (vīragotra), n. familia de héroes.

वीरगोष्ठी (vīragoșthī), f. conversación entre héroes.

वीरचक्र (vīracakra), n. ejército de héroes.

वीरचक्षुष्मत् (vīracakșuṣmat), mfn. que tiene ojos de héroe.

वीरचरित (vīracarita), n. hazañas de héroes.

वीरचर्य (vīracarya), m. hechos heroicos, hazañas aventuradas.

वीरजनन (vīrajanana), mfn. que produce héroes.

विरतम (vīratama), m. hombre muy fuerte y poderoso, héroe eminente.

वीरतर (vīratara), mfn. más fuerte, más valiente; m. gran héroe.

वीरता (vīratā), n. heroísmo, hombría.

वीरनाथ (vīranātha), mfn. que tiene un héroe como protector.

वीरपत्नी (vīrapatn̄i), f. esposa de un héroe.

वीरपाण (vīrapāna), n. bebida de guerreros o de héroes.

वीरपुरुष (vīrapurușa), m. hombre heroico, héroe.

वीरपेशस् (vīrapeśas), m. que constituye el adorno de los héroes.

वीरप्रजायिनी (vīraprajāyin̄i), f. madre de un héroe.

वीरप्रसवा (vīraprasavā), f. mujer que procrea héroes.

वीरभट (vīrabhața), m. guerrero, héroe.

वीरभद्र (vīrabhadra), m. héroe distinguido.

वीरभवत् (vīrabhavat), m. su heroica majestad (fórmula de tratamiento reverencial).

वीरभार्या (vīrabhāryā), f. esposa de un héroe.

वीरभाव (vīrabhāva), m. naturaleza heroica, heroísmo.

वीरमात (vīramātr $)$, f. madre de un niño varón o de un héroe.

वीरमानिन् (vīramānin), mfn. que se considera a sí mismo un héroe.

वीरमार्ग (vīramārga), m. el trayecto o la carrera de un héroe.

वीरयोगवह (vīrayogahava), mfn. que apoya a los hombres o a los héroes.

वीरल्लित (vīralalita), n. forma natural de actuar el héroe.

वीरलोक (vīraloka), m. mundo de los héroes.

वीरवक्षण (vīravakșaṇa), mfn. que fortalece o refresca a los héroes.

वीरवत् (vīravat), mfn. varonil, heroico.

वीरवत्सा (vīravatsā), f. madre de un héroe.

वीरवर (vīravara), m. mejor de los héroes.

वीरवाक्य (vīravākya), n. palabra heroica.

वीरवाद (vīravāda), m. fama heroica, gloria.

वीरविद् (vīravid), mfn. que procura hombres o héroes.

वीरव्यूह (vīravyūha), m. despliegue militar heroico o atrevido.

वीरव्रत (vīravrata), n. heroísmo.

वीरशयन (vīraśayana), n. lecho, formado con flechas, de un héroe muerto o herido.

वीरशायिन् (vīraśāyin), mfn. que yace, como héroe muerto o herido, en un lecho de flechas.

वीरशुष्म (vīraśușma), mfn. que tiene fuerza o valor heroico.

वीरश्रेष्ठ (vīraśreștha), m. héroe sin igual.

वीरसमन्वित (vīrasamanvita), $\mathrm{mfn}$. atendido o acompañado por héroes.

Doi: https://doi.org/10.15517/rfl.v46i1.41159 / URL: https://revistas.ucr.ac.cr/index.php/filyling/index 
वीरसू ( $v \bar{\imath} r a s \bar{u})$, f. madre de un héroe.

वीरसेन (vīrasena), m. ejército de héroes.

वीरस्थान (vīrasthāna), n. lugar o condición de héroe.

वीरहण (vīrahana), mfn. que mata a un héroe.

वीरासन (vīrāsana), n. pose de héroe.

वीरेन्द्र (vīrendra), m. jefe de los héroes.

वीरेश (vīreśa), m. jefe de los héroes.

वीरेश्वर (vīreśvara), m. jefe de los héroes.

वीर्य (vīrya), n. hombría, valor, fuerza, poder, energía, heroísmo, hecho heroico, vigor varonil, virilidad, semen viril, eficacia, veneno, esplendor, lustre, dignidad, consecuencia.

Se contabilizan cincuenta y nueve voces. Entre los cuarenta y cinco sustantivos, destacan vīra (héroe) y vīrya (heroísmo). Todos los demás son compuestos de vīra-: veinte masculinos referidos al "héroe" (vīra, vīrakița, vīratama, vīrapurușa, vīrabhața, vīrabhadra, vīraśreștha, vīrabhavat, vīravara -las dos últimas son formas de tratamiento-), a sus "acciones" (vīracarya, vīramārga), a sus "atributos" (vīrapeśas), a sus "cualidades" (vīrabhāva, vīravāda) y a su "ámbito de acción" (vīraloka, vīravyūha, vīrasena, vīrendra, vīreśa, vīreśvara); once femeninos, referidos principalmente a la "madre" del héroe (vīrakarā,

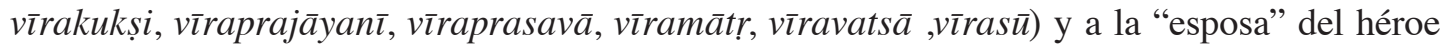
(vīrapatnī, vīrabhāryā), pero también a su "ámbito de acción" (vīragati) y a su "palabra" (vīragoșthī); y, por último, catorce neutros referidos a sus "genitales" (vīrakarma), sus "acciones" (vīrakarman, vīracarita), sus "atributos" (vīrapāṇa, vīraśayana), sus "cualidades" (vīrata, vīralalita, vīravrata, vīrasthāna, vīrāsana, vīrya), su "ámbito de acción" (vīragotra, vīracakra) y su "palabra" (vīravākya). La familia léxica se completa con catorce adjetivos (vīrakāma, vīracakșușmat, vīrajanana, vīratara, vīranātha, vīramānin, vīrayogahava, vīravakșana, vīravat, vīravid, vīraśāyin, vīraśușma, vīrasamanvita, vīrahaṇa) y una raíz verbal $(2 v \bar{\imath} r)$.

Según Monier-Williams (2008, p. 1005), vīra remite a (1) "hombre, hombre valiente o eminente, héroe, jefe" (Rg-Veda); (2) "héroe (opuesto a un dios)" (Religious Thought and Life in India); (3) "esposo" (Mahābhārata, Rāmāyaṇa, Purānas); (4) "hijo" (R.g-Veda, AtharvaVeda, Brāhmaṇas, Gṛhya-Śrauta-Sūtra); (5) "macho" (Atharva-Veda, Śāṃkhāyana-ŚrautaSūtra); (6) "adepto" (Rudrayāmala); (7) (dram.) "heroísmo (uno de los 8 rasas)" (Nātya-Śāstra, Daśarūpa, Sāhitya-Darpaṇa); (8) "actor" (Wilson); "fuego, fuego sagrado o sacrificial" (lexicógrafos). Böhtlingk y Roth (1855), por su parte, registran (1) "hombre", (2) "gente", (3) “dioses", (4) "marido", (5) "hijo", (6) "macho", (7) "tono heroico", (8) "iniciado", (9) "fuego" y (10) "planta".

En relación con el uso del término en el drama, cabe destacar que, de manera similar a lo ocurrido en Grecia, en India la heroicidad épica sirve de base para el desarrollo de la posterior heroicidad dramática ${ }^{1}$.

Por otra parte, en cuanto al sentido primario de "hombre", es posible establecer el siguiente paralelismo: del sánscrito vīra (hombre) deriva vīrya (valor), del mismo modo que del

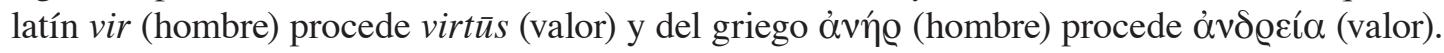
La heroicidad, pues, es una cualidad esencialmente masculina.

Así, el Nātya-Śāstra (Tratado de danza) de Bharata (s. I a.C. - s. III d.C.) desarrolla la teoría de los ocho rasas (sabores): śrnngāra (amor), vīra (heroísmo), bībhatsa (aversión), raudra (ira), hāsya (alegría), bhayānaka (terror), karuna (piedad) y adbhuta (asombro). Y el Daśa-Rūpa (Las diez formas del drama) de Dhanañjaya (s. X d.C.) se refiere propiamente a la figura del héroe dramático. 


\subsection{Campo semántico de la heroicidad en sánscrito}

En sánscrito, existen, además de vīra (héroe), los términos śūra, vikrānta y mahāvīra para referirse a esta figura. Suura, de la raíz ŚSU = ŚVI (crecer), se relaciona con los sustantivos śavas (incremento) y śuna (prosperidad), así como con el adjetivo śūna (hinchado). Se refiere al heroísmo en tanto aumento de la fuerza, el poder y el valor. Por su parte, vikrānta, del prefijo vi- (contra) y la raíz KRAM (acercarse), alude a la capacidad de ataque del héroe, que, en el ámbito de la épica sánscrita, se lleva a cabo mediante la destreza con el arco (en la épica griega, Odiseo lo emplea para vengarse de los pretendientes). Finalmente, mahāvīra, compuesto de vīra con el adjetivo mahat (grande), enfatiza la condición de superioridad del héroe con respecto al resto de los seres humanos. El término se popularizó como nombre del fundador de la religión jainista.

El concepto central asociado a la figura heroica es dharma (ley psico-socio-cósmica). Este constituye uno de los cuatro fines de la vida en el hinduismo: artha (lo material), kāma (el amor), dharma (el deber) y mokșa (la liberación). En su análisis de las filosofías de la India, Zimmer (1965) relaciona el dharma con la ley universal, el deber, la función social, la vocación, la norma moral, la justicia ideal, la virtud y la perfección (en este último sentido, se

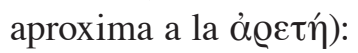

\footnotetext{
El sustantivo sánscrito dharma, de la raíz dhr-, "sostener, portar, llevar" (en latín: fero; cf. el anglosajón: faran, "viajar") significa "lo que sostiene, mantiene unido o levantado" [...] el dharma se refiere no solo a todo el contexto de la ley y de la costumbre (religión, usos, estatutos, observancias de casta o de secta, maneras, modos de comportamiento, deberes, ética, buenas obras, virtud, mérito moral o religioso, justicia, piedad, imparcialidad), sino también a la cualidad, carácter o naturaleza esencial del individuo como resultado de lo cual su deber, función social, vocación o norma moral son lo que son [...] La palabra dharma no solo implica una ley universal que gobierna y sostiene el cosmos, sino también leyes particulares o inflexiones de "la ley", que son naturales a cada clase especial o modificación de la existencia [...] El dharma es la justicia ideal que ha cobrado vida [...] De ahí que la "virtud" sea conmensurable con la perfección que uno alcanza en el ejercicio de su papel (Zimmer, 1965, p. 137).
} siguiente:

Por su parte, Das (2008), en su presentación al libro V del Mahābhārata, afirma lo

En medio de estas dos posturas yace la pregunta fundamental del héroe épico indio: ¿Cómo vivir la vida? ¿Consiste la buena vida en morir joven en batalla e ir al cielo? ¿O debería uno vivir una vida larga, pacífica y quizás ordinaria, de dharma, no violencia y compasión? (Das, 2008, p. xvi; traducción del autor).

Con base en estas apreciaciones, se realizará el análisis de seis voces del campo semántico de la heroicidad en sánscrito.

\subsection{1 अहिंसा (ahims $\bar{a}), f$.}

Procede del prefijo privativo $a$ - y de la raíz HAN (matar, dañar). En Monier-Williams (2008, p. 125), se registran los sentidos de (1) "ausencia de daño hacia algo, inocuidad (una de las virtudes cardinales de la mayoría de las sectas hindúes, pero particularmente de budistas y jainistas)" (Cāndogya-Upaniṣad, Nirukta, Manava-Dharma-Śāstra) y de (2) "seguridad, confianza" (Śatapatha-Brāhmaṇa, Aitareya-Upanișad). El concepto se popularizó en el siglo $\mathrm{XX}$ gracias a la figura de Gandhi, aunque ya aparece, ligado al comportamiento del héroe, desde la Gītā (16.1-3). 


\subsection{2 क्षत्रिय (kșatriya), $m$.}

Se remonta a la raíz 1 KȘI (gobernar). Monier-Williams (2008, p. 325) brinda esta información: "miembro del orden militar o gobernante (que en tiempos posteriores constituyó la segunda casta)" (Atharva-Veda, Śatapatha-Brāhmaṇa, Aitareya-Brāhmaṇa, KātyānaŚrauta-Sūtra, Manava-Dharma-Śāstra). En el hinduismo, hay cuatro jātis (nacimientos): brāhmaṇa (sacerdote), kṣatriya (noble, guerrero), vaiśya (agricultor, comerciante) y śūdra (sirviente). Como en la Grecia homérica, nobleza y aptitud militar son complementarias.

\subsection{3 दया $($ day $\bar{a}), f$.}

Deriva de la raíz DAY (tener piedad por). Su sentido (Monier-Williams, 2008, pp. 469470) es "simpatía, compasión, piedad" (Mahābhārata, Pañcatantra, Bhartrhari). A diferencia del héroe épico griego, cuya $\mu \varepsilon \gamma \alpha \lambda$ o $\psi v \chi i ́ \alpha$ (magnanimidad) es parte integral de su heroicidad, el héroe épico indio, puede optar por la compasión, pero como alternativa al código guerrero.

\subsection{4 युद्ध (yuddha), $n$.}

Se remonta a la raíz 1 YUDH (pelear). Monier-Williams (2008, pp. 854-855) brinda esta información: "batalla, lucha, guerra" (Rg-Veda). El término aparece como primer elemento del compuesto con el que se nombra al mayor de los cinco hermanos Pāṇdavas que protagonizan el Mahābhārata: Yudhișțhira, 'el fuerte en el combate', de la raíz 1 YUDH y el adjetivo sthira (fuerte).

\subsection{5 विक्रान्त (vikrānta), $m f n$.}

Su base es la raíz KRAM (acercarse). Monier-Williams (2008, p. 955) da, para la épica, los sentidos de "valiente, atrevido, fuerte, poderoso, victorioso" (Mahābhärata). Varias voces de su familia léxica coinciden con esta acepción heroica, por ejemplo: vi-KRAM (mostrar valor, atacar, asaltar, pelear), vikrama (valor, coraje, heroísmo, poder, fuerza), vikramana (avance audaz, coraje, heroísmo, fuerza, poder), vikrānti (heroísmo, valor, coraje, fuerza, poder) y vikrāntr (héroe).

\subsection{6 स्वर्ग (svarga), $m$.}

Procede de la raíz 2 SVAR (brillar). En Monier-Williams (2008, p. 1281), se registran los sentidos de "cielo, morada de la luz y de los dioses, gozo celestial, cielo de Indra, paraíso". Situado en el monte Meru (como el monte Olimpo griego), es un cielo temporal. A diferencia de la Grecia homérica, cuya noción del tiempo es lineal (Aquiles está entre los vivos en la Ilíada y entre los muertos en la Odisea), en el hinduismo, el tiempo se concibe como cíclico. Así, si la muerte sigue a la vida, después, esta sigue a aquella nuevamente. El cielo es parte del saṃsāra (transmigración) que experimentan las almas individuales hasta conseguir la liberación y unirse al alma universal. En el Mahābhārata (5.125.15), se afirma "Si consideramos el deber propio en batalla, Mādhava, entonces, muertos por las flechas en el momento oportuno, alcanzaremos el cielo". 


\section{Comparación de la heroicidad}

Las nociones griega e india de la heroicidad tienen un mismo punto de partida: una

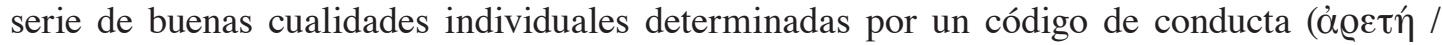
dharma), las cuales son valoradas negativa o positivamente por un grupo social privilegiado

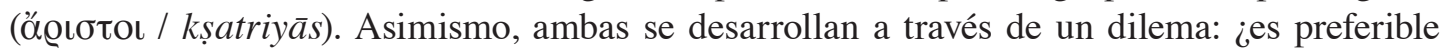
rechazar el camino de la heroicidad y tener una vida larga y orientada a la paz (vóotos / ahims $\bar{a}$, day $\bar{a})$, o, por el contrario, abrazar la vía heroica y optar por una vida breve y dedicada

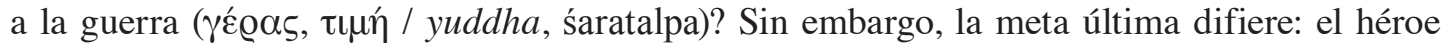

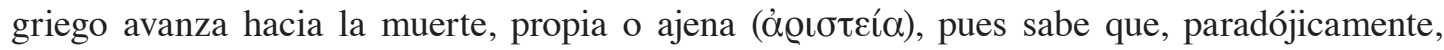

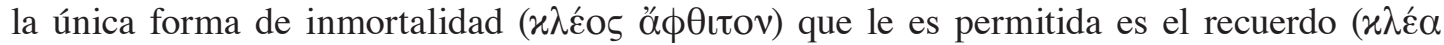
$\hat{\alpha} v \delta \varrho \omega ̂ v)$; el héroe indio, en cambio, trasciende la muerte (svarga), la cual no es sino una etapa del ciclo (saṃsāra), a fin de obtener la liberación (mokṣa).

\section{Conclusiones}

El estudio de familias léxicas y campos semánticos ha permitido la elaboración de dos pares de corpora paralelos: por un lado, 13 voces de la familia léxica de j门ow- y 17 del campo semántico de la heroicidad en griego; por otro, 60 voces de la familia léxica de वीर् y 7 del campo semántico de la heroicidad en sánscrito. En lengua griega, gracias a los numerosos análisis críticos sobre la moral en este ámbito, se aprecia una mayor cantidad de palabras pertenecientes al campo semántico; a su vez, en sánscrito, debido a la alta productividad de los procesos de derivación y composición en dicha lengua, la familia léxica es más numerosa.

El abordaje lexicográfico ha ayudado en el contraste de nociones. Los diccionarios de Bailly (2000) y Monier-Williams (2008) poseen la ventaja de citar las fuentes literarias en que aparecen los términos. Esto ha hecho posible centrar el estudio en la heroicidad épica. Así, se ha postulado una noción griega de heroicidad centrada en la muerte (mortalidad / inmortalidad) y una noción india de la heroicidad orientada a la liberación (del ciclo de las reencarnaciones).

\section{Bibliografía}

Artigas, M. (1998). Propuestas metodológicas para el estudio del léxico. Estudios Románicos, 10, 9-32.

Bailly, A. (2000). Diccionaire grec-français. Paris: Hachette.

Berenguer, J. (2002). Gramática griega. Barcelona: Bosch.

Böhtlingk, O. y Roth, R. (1855). Grosses Petersburger Wörterbuch. Sankt Petesburg: Russlands.

Das, G. (2008). Foreword. Mahābhārata. Book Five. Preparations for War. Volume One (K. Garbutt, trad.) (pp. xv-xxv). New York: The Clay Sanskrit Library.

Dodds, E. (1986). Los griegos y lo irracional. Madrid: Alianza.

Jaeger, W. (2004). Paideia. México: Fondo de Cultura Económica.

Larrañaga, H. (1991-92). Aquiles, héroe de héroes. Revista de Estudios Clásicos, 22, 65-107.

Lasso de la Vega, J. (1963). Ética homérica. En L. Gil (Ed.), Introducción a Homero (pp. 289316). Madrid: Ediciones Guadarrama. 
Lesky, A. (1989). Historia de la literatura griega. Madrid: Gredos.

Liddell, H. y Scott, R. (1843). A Greek English Lexicon. Oxford: University Press. Recuperado de http://www.perseus.tufts.edu

Monier-Williams, M. (2008). Sanskrit-English Dictionary. New Delhi: Munshiram Manoharlal.

Montes, M. (2006). El miedo al desorden: Estrategias de recuperación del equilibrio social en el mito iliádico. Gerión, 24(1), 119-141.

Nagy, G. (1999). The Best of the Achaeans. Maryland: The Johns Hopkins University Press.

Real Academia Española (RAE). (2018). Diccionario de la Lengua Española. Recuperado de http://www.rae.es/

Segura, S. (2003). Nuevo diccionario etimológico latín-español y de las voces derivadas. Bilbao: Universidad de Deusto.

Watkins, C. (2000). The American Heritage Dictionary of Indo-European Roots. Boston-New York: Houghton Mifflin Company.

West, M. (2007). Indo-European Poetry and Myth. Oxford: Oxford University Press.

Zimmer, H. (1965). Filosofías de la India. Buenos Aires: Editorial Universitaria de Buenos Aires. 
